\title{
SISTEMAS SOCIOECOLÓGICOS NO EXTREMO SUL DA BAHIA: UMA ABORDAGEM A PARTIR DOS SERVIÇOS ECOSSISTÊMICOS EM COMUNIDADES RURAIS
}

\author{
AUTOR: PAULO AFONSO DE ANGELI NETO \\ CO-AUTOR: GUINEVERRE ALVAREZ MACHADO DE MELO GOMES \\ CO-AUTOR/ORIENTADOR: FREDERICO MONTEIRO NEVES
}

\begin{abstract}
Resumo: Ecossistemas conservados e bem manejados, como florestas e manguezais, têm um papel fundamental para a sobrevivência de comunidades urbanas e rurais, especialmente no contexto do aquecimento global contemporâneo que impõe a necessidade da adaptação e mitigação para a humanidade. As florestas e seus serviços ecossistêmicos também são afetados negativamente pelas mudanças climáticas. Nesse contexto, este trabalho tem como objetivo identificar e analisar serviços ecossistêmicos em projetos de restauração florestal na região do extremo sul da Bahia, buscando compreender a relação das comunidades com as florestas e seu potencial de resiliência. Para tal, tem como foco as ações do Programa Arboretum e três de seus núcleos de gestão florestal. Múltiplas estratégias foram utilizadas para a coleta de dados, como análises bibliográfica e documental, grupos focais e entrevistas semiestruturadas. Os resultados indicam que nos remanescentes florestais pesquisados, as comunidades percebem e utilizam dos serviços ecossistêmicos, principalmente os de provisão, como frutas, sementes e plantas medicinais. Os núcleos pesquisados não podem ser considerados sistemas socioecológicos devido a limitada relação que possuem com a floresta, não sendo dependentes da mesma para sua sobrevivência. Nesse contexto, o Programa Arboretum tem contribuído positivamente para o uso sustentável e proteção das florestas por meio das redes de sementes e mudas.
\end{abstract}

Palavras-chave: Serviços ecossistêmicos, extremo sul baiano, mata atlântica, arboretum. 